\title{
Psychometric Properties of the Greek-University of California, Los Angeles Loneliness Scale-Version 3 in a Sample of People with Human Immunodeficiency Virus
}

\author{
Polyxeni Pikea1, Efi Parpa², Eleni Tsilika², Antonis Galanos², Kyriaki Mystakidou2* \\ ${ }^{1}$ OKANA, Antidrug Center, Athens, Greece \\ ${ }^{2}$ Pain Relief and Palliative Care Unit, Department of Radiology, Areteion Hospital, School of Medicine, National and Kapodistrian \\ University of Athens, Athens, Greece \\ Email: *mistakidou@yahoo.com
}

How to cite this paper: Pikea, P., Parpa, E., Tsilika, E., Galanos, A. and Mystakidou, K. (2016) Psychometric Properties of the GreekUniversity of California, Los Angeles Loneliness Scale-Version 3 in a Sample of People with Human Immunodeficiency Virus. Worla Journal of AIDS, 6, 157-168.

http://dx.doi.org/10.4236/wja.2016.64018

Received: August 30, 2016

Accepted: November 20, 2016

Published: November 23, 2016

Copyright $\odot 2016$ by authors and Scientific Research Publishing Inc. This work is licensed under the Creative Commons Attribution International License (CC BY 4.0).

http://creativecommons.org/licenses/by/4.0/

\begin{abstract}
Aims: The aim of this study was to validate the Greek translation of the University of California, Los Angeles Loneliness Scale (UCLA) in Greek adults with HIV. Methods: The UCLA Loneliness scale (version 3) was administered to 140 people with HIV. Participants also completed the Greek Hospital Anxiety and Depression Scale (G-HADS). Validity and reliability analyses were performed. Results: The Cronbach's $\alpha$ coefficient for the total UCLA score was 0.9 . Test-retest reliability analysis in a subgroup of patients $(n=40)$ revealed good short-term stability over a 2-week interval (ICC $0.8-0.9, \mathrm{p}<0.0005)$. Exploratory factor analysis generated a three factors structure for the Greek translation. Convergent validity was supported through the scale's high correlations with G-HADS anxiety $(0.382, \mathrm{p}<0.01)$ and depression (0.524, $\mathrm{p}<0.005)$. Conclusion: The Greek UCLA Loneliness scale (version 3 ) is a valid and reliable instrument that can be usefully implemented into clinical practice in order to diagnose and treat loneliness among the Greek HIV positive patients.
\end{abstract}

\section{Keywords}

UCLA Loneliness Scale, People with HIV, Reliability, Validity

\section{Introduction}

Human immunodeficiency virus (HIV) is the virus that causes AIDS (acquired immu- 
nodeficiency syndrome). People with HIV have to deal with loneliness, stigma, depression, anxiety, as well as social and health consequences [1].

Feeling of loneliness is the unpleasant experience when peoples' network of social relationships is deficient including notions of isolation and disconnection [2] [3], associated with mental and health outcomes [4].

There are many definitions about loneliness either as a biological construct or as a discrepancy between desired and actual social relationship [5] [6] [7].

Moustakas [8] described the existential loneliness as the forced separation from others. Perlman and Peplau [3], explained loneliness as a result of dysfunctional relationships, with impact to humans stated that there is a significant difference between the subjective feeling of loneliness and the objective state of social isolation. Although there is a different theoretical background behind these definitions, they all agree in the impact of loneliness in people. Lonely individuals perceive the social world as a threatening place, expect more negative social interactions, and recall more negative social information so they distance themselves from the social world. This loop creates feelings of hostility, stress, pessimism, anxiety and low self esteem activating the neurobiological and behavioral mechanisms that affect health outcomes [9] [10] [11].

People with HIV have to deal not only with the infection, but also with the emotional stress caused by the fact that HIV is a chronic, life threatening disease, and the prejudice that blames the people for being HIV, positive. These stressors, psychosocial factors the social isolation, poor social support and loneliness make people with HIV experience a cluster of symptoms that are extremely complicated [12].

Loneliness is one of the most important sources of emotional and psychological distress affecting life of people with HIV, as it is the result of emotional and social isolation, existential loneliness and stigmatization, as a common psychological symptom affects almost $50 \%$ of the people with HIV [13]. In addition, the relationship between loneliness, stress and inflammation seemed to be critical to understanding the health implications of loneliness [14]. Similarly, compared with people more socially connected, people who experienced loneliness exhibited less natural killer cell activity [15] while men infected with HIV had higher human herpesvirus 6 antibody titers related to the more socially connected counterparts [16]. Additionally, loneliness in people with HIV seemed to be related with CD-4 (cluster of differentiation 4) as more lonely patients have decreased CD-4 than less lonely patients [17].

Clinicians usually underestimated the importance of loneliness focusing more with the infection and/or the appropriate treatment [13].

Many instruments have been constructed measuring loneliness, in different population: a) The De Jong Gierveled short scales for emotional and social loneliness [18], b) The Duke Social Support Index [19] and c) the Loneliness scale (UCLA) [20]. Russell [20] was the first that evaluated the psychometric properties of UCLA-version 3 using data from prior studies of teachers, college students and elderly. The results showed 
that UCLA was highly reliable, with internal consistency ranging from 0.89 to 0.94 , and test retest reliability over a year period $(\mathrm{r}=0.73)$.

Several studies [21]-[26] have shown the UCLA questionnaire is a valid, objective and reliable instrument.

The UCLA is a systematic attempt to embody verbal descriptors in loneliness assessment in a sample of Greek HIV patients. The aims were to access the Greek version of the UCLA for its applicability, reliability, and validity on a sample of people with HIV.

\section{Methods}

\subsection{Patients and Procedure}

The study took place between January 2014 and July 2014 in the Greek General Hospital Red Cross, in Special Infection Unit in Athens Greece. The sample consisted of Greek patients with an HIV diagnosis. The questionnaire was administered in two different times with an interval of 7 days.

Inclusion criteria were the following: a) participants were at least 18 years old b) participants should be capable of communicating effectively with the study personnel with fluency in Greek language. Exclusion criteria included recent diagnosis.

The original validation sample consisted of $140 \mathrm{HIV}$ patients among the 600 patients that are treated there, and it was drawn using the method of random sampling. They all completed the questionnaire and 40 of them completed the same questionnaire 7 days later for test re-test analysis. All participants have completed a written informed consent for their participation in the current study. Additionally, hospital's ethics committee approved this study, which was conducted according to Declaration of Helsinki principles and according to guidelines for good clinical practice.

The sociodemographic characteristics are presented in Table 1.

\subsection{Instruments}

\subsubsection{UCLA}

The UCLA Loneliness Scale (version 3), [20] is a 20-item scale that measures the subjective feeling of loneliness. For each question, there is a 4-point scale $(1=$ never, $2=$ rarely, 3 = some times, 4 = always). The range of scores is between 20 to 80 (20 = "I don't feel loneliness" and $80=$ "I feel very lonely". Higher scores indicate higher levels of loneliness. UCLA Loneliness scale is a valid and reliable instrument, with cronbach $\alpha$ $(\mathrm{alpha})=0.89$ to 0.97 and test-retest reliability $(\mathrm{r}=0.73)$.

\subsubsection{HADS}

The Greek version of the Hospital Anxiety and Depression Scales (G-HADS) is a self assessment mood scale specifically designed for use in hospital setting. It is a brief self-report 14-item scale designed to measure the two most common aspects of mood disorder (anxiety and depression) on a 0 - 3 verbal numerical scale (0: No distress-3: maximum distress). It is a useful screening measure for anxiety and depression with cronbach's alpha for HADS-A: 0.83 and for HADS-D: 0.82 [27]. 
Table 1. Patient's demographic characteristics.

\begin{tabular}{cccc}
\hline & & $\mathrm{N}$ & $\%$ \\
\hline \multirow{2}{*}{ Gender } & Male & 121 & 86.4 \\
& Female & 19 & 13.6 \\
& Primary & 19 & 13.6 \\
Education & High school & 57 & 40.7 \\
& University & 44 & 31.4 \\
& MSc-Phd & 20 & 14.3 \\
Family status & Single & 86 & 61.4 \\
& Married/in relationship & 29 & 20.7 \\
& Homosexual & 25 & 17.9 \\
Occupation & Pensioner & 22 & 15.7 \\
& Employee & 19 & 13.6 \\
& Freelance & 54 & 38,6 \\
Income & Unemployed & 45 & 32.1 \\
& $<500 €$ & 45 & 32.1 \\
& $500-1500 €$ & 83 & 59.3 \\
Country of origin & $>1500 €$ & 12 & 8.6 \\
& Greece & 126 & 90.0 \\
& Other & 14 & 10.0 \\
& Mean \pm SD & Min & Max \\
& $43.10 \pm 11.96$ & 20 & 69 \\
& $9.00 \pm 7.26$ & 1 & 28 \\
\hline
\end{tabular}

\subsection{Translation}

The "forward-backward" procedure was applied to translate the UCLA scale from English to Greek. The questionnaire was first translated into Greek by two independent translators whose native language was Greek. The translators were healthcare professsionals and familiar with the terminology. The instrument was then back translated into English by another two independent translators whose native language was English. Emphasis was given on conceptual and cultural equivalence in both ways of translation. The new back-translated version was then compared with the original version to check the validity of the translated version. The next step was comparison of the original and back translation questionnaire by the research team. Finally, a meeting of translators and the research team was held to make a decision about the final version.

\section{Statistical Analysis}

All the data were analysed using SPSS version 17.0 (SPSS Inc., Chicago, IL, USA) and SAS version 7.0 (SAS Institute, Cary, NC, USA) statistical programs. The critical level for significance was chosen at $p<0.05$.

Internal consistency of the UCLA was determined by calculating Cronbach $(\alpha)$ alpha coefficient (with $\alpha=0.7$ indicating sufficient reliability).

The validity of the UCLA was conducted consisted of factor analysis, construct validity and the known group's validity.

Confirmatory factor analysis ( $C F A$ ) was examined to confirm the factor structure as 
suggested by the author of the original validation article. The $C F A$ was analysed using the Analysis of Moment Structure (AMOS) version 7.0. For the rejection or acceptance of the model was based on global fit indices and magnitude of the variance explained by the resulting factors. The global fit indices included: The $\mathrm{X}^{2}$-degrees of freedom $(\mathrm{d} . \mathrm{f})$ ratio $<2.0$, RMSEA $<0: 06$, CFI $>0: 90$, NFI $>0: 90$, GFI $>0.85$, AGFI $>0.85$ indicated an acceptable fit.

Exploratory factor analysis (EFA) using principal component extraction method with Varimax rotation, was conducted to determine the factor structure of the items of the instrument (items with factor loadings $\geq 40$ were retained).

Construct validity of the UCLA was determined by establishing its correlation to the HAD anxiety and depression scales.

Known groups validity of the instrument was examined in terms of the ability of the scale to discriminate between a group of people with a particular trait and the group without the trait. For the current analysis UCLA was assessed in order to reveal the ability of its scales to distinguish between subgroups of people concerning illness duration.

The reliability includes internal consistency reliability and test-retest reliability. Testretest reliability (stability) indicates the stability of peoples' response in time and it was determined by calculating ICC. To assess test-retest reliability, we selected randomly 40 people for the second measure 7 days after the initial assessment.

\section{Results}

\subsection{Descriptive Analysis}

From our sample, 121 were males and 19 females. Descriptive statistics showed that the mean total score for UCLA was $42.59( \pm 11.03)$. For the factor 1 , the mean score was $20.08( \pm 6.01)$, for factor $2: \mathrm{x}=10.66 \pm 3.69$ and for factor 3 the mean score was 9.24 $( \pm 3.01)$ (Table 2).

Confirmatory factor analysis (CFA): the one-factor model was conducted by confirmatory factor analysis giving unacceptable global fit indices. The resulting global fit indices $\mathrm{X}^{2}=113.23, p<0.0005$, chi-square-degrees of freedom (d. f.) ratio $=2.45$, RMSEA $=$ $0.102, \mathrm{CFI}=0.72, \mathrm{NFI}=0.68, \mathrm{GFI}=0.59, \mathrm{AGFI}=0.57$ showed that the one factor solution proposed by the author should be rejected.

Table 2. Descriptive statistics of questionnaires.

\begin{tabular}{ccccc}
\hline & Mean & SD & Min & Max \\
\hline Social loneliness & 20.08 & 6.01 & 9.00 & 35.00 \\
Psychological loneliness & 10.66 & 3.69 & 5.00 & 20.00 \\
Isolation & 9.24 & 3.01 & 5.00 & 16.00 \\
Total score & 42.59 & 11.03 & 21 & 67 \\
HAD anxiety & 7.83 & 4.31 & 1.00 & 17.00 \\
HAD depression & 3.88 & 3.16 & .00 & 13.00 \\
\hline
\end{tabular}


Exploratory factor analysis: Using a minimum eigenvalue of 1.0 as the extraction criterion for factors, 3 factors were extracted. Factor 1 explained $41.9 \%$ of the total variance, Factor 2, 9.7\% and Factor 3 explained $7.5 \%$ of the total variance. Factor loadings were high, ranging for factor 1 from 0.54 to 0.8 , for factor 2 from 0.63 to 0.86 and finally for factor 3 from 0.5 to 0.83 (Table 3).

Factor 1 was labeled as "social loneliness" including the following items: 2) How often do you feel that you lack companionship? 3. How often do you feel that there is no one you can turn to? 4. How often do you feel alone? 7. How often do you feel that you are no longer close to anyone? 8 . How often do you feel that your interests and ideas are not shared by those around you? 11. How often do you feel left out? 12. How often do you feel that your relationship with others is not meaningful? 14. How often do you feel isolated? 18. How often do you feel that people are around you but not with you?

Factor 2 was labeled as "psychological loneliness" includes the following: 13. How often do you feel that no one really knows you well? 15. How often do you feel that you can found companionship when you want it? 16. How often do you feel that there are people who really understand you? 19. How often do you feel that there are people you can talk to? 20. How often do you feel that there are people you can turn to?

Table 3. Eigenvalues and variance explained.

\begin{tabular}{|c|c|c|c|c|c|c|}
\hline \multicolumn{7}{|c|}{ Total Variance Explained } \\
\hline \multirow{2}{*}{ Component } & \multicolumn{3}{|c|}{ Initial Eigenvalues } & \multicolumn{3}{|c|}{ Rotation Sums of Squared Loadings } \\
\hline & Total & $\%$ of Variance & Cumulative \% & Total & $\%$ of Variance & Cumulative \% \\
\hline 2 & 1.849 & 9.730 & 51.693 & 3.483 & 18.330 & 43.954 \\
\hline 3 & 1.443 & 7.593 & 59.286 & 2.913 & 15.332 & 59.286 \\
\hline 5 & 0.948 & 4.990 & 69.642 & & & \\
\hline 6 & 0.862 & 4.537 & 74.179 & & & \\
\hline 7 & 0.668 & 3.515 & 77.694 & & & \\
\hline 8 & 0.581 & 3.060 & 80.753 & & & \\
\hline 12 & 0.418 & 2.202 & 90.423 & & & \\
\hline 13 & 0.394 & 2.076 & 92.499 & & & \\
\hline 14 & 0.303 & 1.595 & 94.093 & & & \\
\hline 15 & 0.282 & 1.482 & 95.576 & & & \\
\hline 16 & 0.269 & 1.414 & 96.990 & & & \\
\hline 17 & 0.231 & 1.214 & 98.204 & & & \\
\hline 18 & 0.182 & 0.958 & 99.162 & & & \\
\hline 19 & 0.159 & 0.838 & 100.000 & & & \\
\hline
\end{tabular}

Extraction method: principal component analysis. 
Factor 3 was labeled as "isolation" including items: 1. How often do you feel that you are "in tune" with the people around you? 5. How often do you feel part of a group of friends? 6. How often do you feel that you have a lot in common with the people around you? 9. How often do you feel outgoing and friendly? 10. How often do you feel close to people? (Table 4).

\subsection{Reliability}

\subsubsection{Internal Consistency}

In terms of internal consistency, Cronbach's alpha for social loneliness was 0.898 , for psychological loneliness: 0.870 and for isolation: 0.767 . Corrected item subscales were greater than 0.3 ranging from 0.5 to 0.85 indicating strong relationship between individual items and total score (Table 5).

\subsubsection{Test Retest Reliability}

For the stability of the instrument test-retest analysis has been contacted of patients' responses. Forty patients were selected randomly from the sample completed the questionnaire 7 days after the baseline evaluation. Paired samples $t$ test between baseline and follow up assessment yielded no statistically significant differences at two times period (Table 6).

Table 4. Exploratory factor analysis.

\begin{tabular}{cccc}
\hline & & Factors & 3 \\
\cline { 2 - 4 } ITEM2 & 1 & 2 & \\
ITEM3 & 0.807 & & \\
ITEM4 & 0.749 & & \\
ITEM11 & 0.744 & & \\
ITEM12 & 0.737 & & \\
ITEM14 & 0.688 & & \\
ITEM7 & 0.655 & & 0.644 \\
ITEM8 & 0.600 & & \\
ITEM18 & 0.596 & & \\
ITEM19 & 0.546 & 0.865 & \\
ITEM20 & & 0.754 & 0.838 \\
ITEM15 & & 0.692 & \\
ITEM16 & & 0.675 & \\
ITEM13 & & 0.630 & \\
ITEM9 & & & \\
ITEM10 & & & \\
ITEM5 & & & \\
ITEM1 & & & \\
ITEM6 & & & \\
\hline ITE & & & \\
\hline
\end{tabular}

Extraction method: principal component analysis. Rotation method: varimax with Kaiser normalization. Rotation converged in 5 iterations. 
Table 5. Item subscale correlation.

\begin{tabular}{cccc}
\hline & \multicolumn{2}{c}{ Factors } \\
\cline { 2 - 4 } & 1 & 2 & 3 \\
\hline ITEM2 & 0.715 & & \\
ITEM3 & 0.787 & & \\
ITEM4 & 0.795 & & \\
ITEM11 & 0.775 & & \\
ITEM12 & 0.791 & & \\
ITEM14 & 0.742 & & \\
ITEM7 & 0.747 & & \\
ITEM8 & 0.658 & 0.828 & \\
ITEM18 & 0.660 & 0.851 & 0.729 \\
ITEM19 & & 0.820 & 0.775 \\
ITEM20 & & 0.843 & \\
ITEM15 & & 0.719 & \\
ITEM16 & & & \\
ITEM13 & & & \\
ITEM9 & & & \\
ITEM10 & & & \\
ITEM5 & & & \\
ITEM1 & & & \\
ITEM6 & & & \\
\hline
\end{tabular}

Table 6. Test-retest reliability.

\begin{tabular}{ccccc}
\hline \multirow{2}{*}{ ICC $(95 \% \mathrm{CI})$} & \multicolumn{3}{c}{ Paired samples t-test } \\
\cline { 3 - 4 } & & Initial & Reassessment & $p$-value \\
\hline Social loneliness & $0.826(0.69-0.90)$ & $17.30 \pm 4.27$ & $18.20 \pm 5.56$ & 0.293 \\
Psychological loneliness & $0.980(0.96-0.99)$ & $10.33 \pm 3.85$ & $9.97 \pm 3.81$ & 0.101 \\
Isolation & $0.880(0.75-0.94)$ & $8.47 \pm 2.08$ & $9.13 \pm 2.94$ & 0.052 \\
\hline
\end{tabular}

\subsection{Validity}

\subsubsection{Construct Validity}

HADs were used as a gold standard for UCLA to assess the construct validity of the instrument. Statistically significant correlations were found between social loneliness with HAD Anxiety ( $\mathrm{r}=0.382, p<0.005)$, and HAD Depression $(\mathrm{r}=0.431, p<0.005)$. Additionally, statistically significant correlations were found between psychological loneliness with HAD Anxiety $(\mathrm{r}=0.252, p<0.05)$ and HAD Depression $(\mathrm{r}=0.447, p<0.005)$; similarly, the correlations between isolation with HAD Anxiety and HAD Depression were statistically significant (HAD-A, $\mathrm{r}=0.244, p<0.05$, HAD-D, $\mathrm{r}=0.413, p<0.01$ ).

\subsubsection{Known Groups Validity}

The UCLA results showed no differences in between sub-groups of patients (illness duration) considering the social loneliness. However, there are differences illness duration considering psychological loneliness and isolation. Significant mean differences in psychological loneliness were found between 1 year illness duration and more than 1 
year illness duration $(p=0.01)$. Significant mean differences in isolation were found between 1 year illness duration $(\mathrm{x}=7.96)$ and people with more than 1 year illness duration $(p=0.02)$ (Table 7$)$.

\section{Discussion}

Loneliness is a complex experience that affects people with HIV as their social relationships might be deficient including the experience of isolation and disconnection [28]. Therefore, loneliness could be seen either as a temporary state due to specific changes such as moving to a new community or as a trait due to its duration (short or long-term loneliness). For this reason, loneliness assessment through validated measures has become a priority.

A survey that conducted in a region of China with high percent of people with HIV showed that $84.5 \%$ experienced moderate to high levels of loneliness. Social and family support had a negative correlation to loneliness. If people with HIV felt affection and have social support, the negative impacts of loneliness in their psychosocial life could be decreased [25]. In 1993, Laryea \& Gien investigated the role of diagnosis in psychosocial aspects of peoples' life, mostly on relationships. The people expressed feelings of loneliness, stigma, fear of social rejection, uncertainty for their health and they had problems in their relationships with family members and friends. It is worth noting the fact that they could not share these feelings with their family and friends [29].

The current study evaluated the validity and reliability of a Greek translation of the UCLA among people with HIV receiving antiretroviral treatment. The objective of the UCLA was to facilitate the communication of loneliness between people with HIV and health care professionals, and also to supply the appropriate treatment to the patients.

The Greek UCLA was well accepted by patients as questions were asked in a simple and clear manner. The length of time (10 - $15 \mathrm{~min}$ ) for the completion of the questionnaire also was acceptable. In addition, compliance was high, and there were no missing values. It was found to be an easy and usable instrument without special clinician training. Similarly, the psychometric properties presented, support the validity and the reliability of the instrument.

Confirmatory factor analysis of the UCLA Loneliness Scale suggested 3 factors: one single bipolar global loneliness factor and two orthogonal method factors (one for the positive items and another for the negative items) [20]. Three factor-analytic results

Table 7. Known groups validity.

\begin{tabular}{ccccc}
\hline & Illness duration & $\mathrm{N}$ & Mean \pm SD & $p$-value \\
\hline \multirow{2}{*}{ Social loneliness } & 1 year & 24 & $19.54 \pm 4.69$ & 0.633 \\
& More than 1 year & 116 & $20.19 \pm 6.26$ & $8.87 \pm 2.96$ \\
Psychological loneliness & 1 year & 24 & $11.03 \pm 3.72$ & 0.01 \\
& More than 1 year & 116 & $7.96 \pm 2.29$ & 0.02 \\
\hline \multirow{2}{*}{ Isolation } & 1 year & 24 & $9.45 \pm 3.04$ & 116 \\
\hline
\end{tabular}


seem to differ from analyses that conducted in earlier versions of the UCLA Loneliness Scale. The validity issue addressed by these analyses concerned the factor structure of the Greek UCLA Loneliness scale (version 3). In order to evaluate the factor structure an exploratory factor analysis was conducted. A model that hypothesized three factors found to provide an excellent fit to the data and the factor analytic results are in agreement with analyses conducted in other researches using UCLA loneliness Scale. For example, Austin (1983) suggested a three factors analysis: factor 1 concludes all the negatively worded items and the other two factors conclude all the positively worded items [30].

Contrary to our findings different structure was obtained from other researchers. Knight and colleagues [31] and Miller and Cleary [32] presented a two factor structure analysis: one for lonely, negative items and one for non-lonely, positive items. In addition, Mahon [23] used an orthogonal varimax rotation and the two-factor solution was finally explored. Russel (1982) suggested the unidimensionality of the scale consistent to the Danish version of UCLA [33].

The Greek UCLA loneliness Scale discriminated well between subgroups of patients regarding the illness duration. People with HIV found to have higher loneliness and isolation than those with recent diagnosis probably due to the fact that people are feeling lonelier as the time goes by. Regarding the construct validity the three factors revealed low correlation with anxiety subscale and moderate correlation with depression subscale, confirming the strong association of UCLA with depression suggesting depression as the most consistently variable in loneliness.

The study also confirmed stability of the UCLA for a short time interval of 1 week as well as internal consistency. For the total score of Greek UCLA the results showed a high satisfactory and adequate psychometrically Cronbach's $\alpha$ coefficient of 0.91 , which is comparable to alphas reported in previous studies ranging from 0.89 to 0.97 . Correlation between items and subscales also were high further supporting internal consistency of the scale.

The current study enriches the variety of populations in studies that UCLA loneliness scale has been used. One limitation of the current study is the small sample size. People with HIV that are treated in Special Infection Units have been asked to participate (as target group) in a plethora of studies researching HIV aspects, so they tend to be tired and deny the participation. Additionally, another limitation of the current study is that women are under-represented. However, the psychometric data presented here supported the reliability and validity of the Greek UCLA loneliness Scale (version 3).

\section{References}

[1] Gore-Felton, C. and Koopman, C. (2008) Behavioral Mediation of the Relationship between Psychosocial Factors and HIV Disease Profession. Psychosomatic Medicine, 70, 569-574. http://dx.doi.org/10.1097/PSY.0b013e318177353e

[2] Cacioppo, J.T., Hawkley, L.C., Crawford, L.E., Ernst, J.M., Burleson, M.H., Kowalewski, R. B. and Berntson, G.G. (2002) Loneliness and Health: Potential Mechanisms. Psychosomatic Medicine, 64, 407-417. http://dx.doi.org/10.1097/00006842-200205000-00005 
[3] Perlman, D. and Peplau, L.A. (1981) Toward a Social Psychology of Loneliness. In: Duck, S.W. and Gilmour, R., Eds., Personal Relationships in Disorder, Academic Press, London.

[4] Cacioppo, J.T., Ernst, J.M., Burleson, M.H., McClintock, M.K., Malarkey, W.B., Hawkley, L.C. and Berntson, G.G. (2000) Lonely Traits and Concomitant Physiological Processes: The MacArthur Social Neuroscience Studies. International Journal of Psychophysiology, 35, 43-54. http://dx.doi.org/10.1016/s0167-8760(99)00049-5

[5] Ettema, E.J., Derksen, L.D. and Leeuwen, E. (2010) Existential Loneliness and End-of-Life Care: A Systematic Review. Theoretical Medicine and Bioethics, 31, 141-169. http://dx.doi.org/10.1007/s11017-010-9141-1

[6] Masi, C.M., Chen, H.Y., Hawkley, L.C. and Cacioppo, J.T. (2013) A Meta-Analysis of Interventions to Reduce Loneliness. Personality and Social Psychology Review, 15, 10-11.

[7] Weiss, R.S. (1989) Reflections on the Present State of Loneliness Research. In: Hojat, M. and Crandall, R., Eds., Loneliness. Theory, Research, and Applications, Sage, Newbury Park, 1-16.

[8] Moustakas, C.E. (1961) Loneliness. Prentice-Hall, New York.

[9] Cacioppo, J.T. and Hawkley, L.C. (2010) Loneliness Matters: A Theoretical and Empirical Review of Consequences and Mechanisms. Behavioral Medicine, 40, 200-215.

[10] Cacioppo, J.T., Hawkley, L.C., Norman, G.J. and Berntson, G.G. (2011) Social Isolation. Annals of the New York Academy of Sciences, 1231, 17-22. http://dx.doi.org/10.1111/j.1749-6632.2011.06028.x

[11] Cohen, S. (2004) Social Relationships and Health. American Psychologist, 59, 676-684. http://dx.doi.org/10.1037/0003-066X.59.8.676

[12] Dixon, D., Cruess, S., Kilbourn, K., Klimas, N., Fletcher, M.A. and Ironson, G. (2010) Social Support Mediates Loneliness and Human Herpesvirus Type 6 (HHV-6): Antibody Titers. Journal of Applied Psychology, 31, 1111-1132.

[13] Nokes, K.M. and Kendrew, J. (2001) Correlates of Sleep Quality in Persons with HIV Disease. The Journal of the Association of Nurses in AIDS Care, 12, 17-22. http://dx.doi.org/10.1016/S1055-3290(06)60167-2

[14] Hawkley, L.C., Bosch, J.A., Engeland, C.G., Marucha, P.T. and Cacioppo, J.T. (2007) Loneliness, Dysphoria, Stress, and Immunity: A Role for Cytokines. In: Plotnikoff, N.P., Ed., Cytokines: Stress and Immunity, CRC Press, Boca Raton, 67-85.

[15] Kiecolt-Glaser, J.K., Ricker, D., George, J., Messick, G., Speicher, C., Garner, W. and Glaser, R. (1984) Urinary Cortisol Levels, Cellular Immunocompetency, and Loneliss in Psychiatric Inpatients. Psychosomatic Medicine, 46, 15-23. http://dx.doi.org/10.1097/00006842-198401000-00004

[16] Broadhead, W.E., Kaplan, B., James, S., Wagner, E., Schoenbach, U., Grimson, R., Heyden, S., Tibblin, G. and Gehlbach, S. (1983) The Epidemiologic Evidence for a Relationship between Social Support and Health. American Journal of Epidemiology, 117, 521-537.

[17] Straits-Troster, K.A., Patterson, T.L., Semple, S.J., Temoshol, L., Roth, P.G. and Grant, I. (2007) The Relationship between Loneliness, Interpersonal Competence, and Immunologic Status in HIV-Infected Men. Psychology \& Health, 9, 205-219. http://dx.doi.org/10.1080/08870449408407481

[18] Gierveld, J. and Tilburg, T. (2010) The De Jong Gierveld Short Scales for Emotional and Social Loneliness: Tested on Data from 7 Countries in the UN Generations and Gender Surveys. European Journal of Ageing, 7, 121-130. http://dx.doi.org/10.1007/s10433-010-0144-6

[19] Koening, H.G., Westlund, R.E., George, L.K., Hughes, D.C., Blazer, D.G. and Hybels, C. 
(1993) Abbreviating the Duke Social Support Index for Use in Chronically Elderly Individuals. Psychosomatics, 34, 61-69. http://dx.doi.org/10.1016/S0033-3182(93)71928-3

[20] Russell, D. (1996) UCLA Loneliness Scale (Version 3): Reliability, Validity, and Factor Structure. Journal of Personality Assessment, 66, 20-40.

http://dx.doi.org/10.1207/s15327752jpa6601 2

[21] Dahbero, L. and Mckee, K. (2014) Correlates of Social and Amotional Loneliness in Older People: Evidence from an English Community Study. Aging and Mental Health, 18, 504514. http://dx.doi.org/10.1080/13607863.2013.856863

[22] Gokler, M.E., Unsal, A. and Arsantas, D. (2014) The Prevelence of Infertility and Loneliness among Women Aged 18 - 49 Years Who Are Living in Semi-Rural Areas in Western Turkey. International Journal of Fertility and Sterility, 8, 155-162.

[23] Mahon, N.E., Yarcheski, T.J. and Yarcheski, A. (1995) Validation of the Revised UCLA Loneliness Scale for Adolescents. Research in Nursing and Health, 18, 263-270.

http://dx.doi.org/10.1002/nur.4770180309

[24] Neto, F. and Barros, J. (2000) Psychosocila Concomitants of Loneliness among Students of Cape Verde and Portugal. Journal of Psychology, 134, 503-514. http://dx.doi.org/10.1080/00223980009598232

[25] Sun, Y.H, Sun, L., Wu, H.Y., Zhang, Z.K., Wang, B. and Cao, H.Y. (2009) Loneliness, Social Support and Family Function of People Living with HIV/AIDS in Anhui Rural Area, China. International Journal of STD \& AIDS, 4, 255-258. http://dx.doi.org/10.1258/ijsa.2008.008348

[26] Tzang, R.F., Yang, A.C., Yeh, H.L., Liu, M.E. and Tsaj, S.J. (2015) Association of Depression and Loneliness with Specific Cognitive Performance in Non-Demented Elderly Males. Medical Science Monitor, 21, 100-104. http://dx.doi.org/10.12659/MSM.891086

[27] Mystakidou, K., Tsilika, E., Parpa, E., Katsouda, E., Galanos, A. and Vlahos, L. (2004) The Hospital Anxiety and Depression Scale in Greek Cancer Patients: Psychometric Analyses and Applicability. Supportive Care in Cancer, 12, 821-825. http://dx.doi.org/10.1007/s00520-004-0698-y

[28] Rusell, D. (1982) The Measurement of Loneliness. In: Peplau, L.A. and Perlman, D., Eds., Loneliness. A Sourcebook of Current Theory, Research and Therapy, Wiley, New York, 81-104.

[29] Laryea, M. and Gien, L. (1993) The Impact of HIV-Positive Diagnosis on the Individual, Part 1. Stigma, Rejection, Loneliness. Clinical Nursing Research, 2, 245-263. http://dx.doi.org/10.1177/105477389300200302

[30] Austin, B.A. (1983) Factorial Structure of the UCLA Loneliness Scale. Psychological Reports, 53, 885-889. http://dx.doi.org/10.2466/pr0.1983.53.3.883

[31] Knight, R.G., Chisholm, B.J., Marsh, N.V. and Godfrey, H.P. (1988) Some Normative, Reliability, and Factor Analytic Data for the Revised UCLA Loneliness Scale. Journal of Clinical Psychology, 44, 203-206. http://dx.doi.org/10.1002/1097-4679(198803)44:2<203::AID-JCLP2270440218>3.0.CO;2-5

[32] Miller, T.R. and Cleary, T.A. (1993) Direction of Wording Effects in Balanced Scales. Education and Psychological Measurement, 53, 51-60. http://dx.doi.org/10.1177/0013164493053001004

[33] Lasgaard, M. (2007) Reliability and Validity of the Danish Version of the UCLA Loneliness Scale. Personality and Individual Differences, 42, 1359-1366.

http://dx.doi.org/10.1016/j.paid.2006.10.013 
Submit or recommend next manuscript to SCIRP and we will provide best service for you:

Accepting pre-submission inquiries through Email, Facebook, LinkedIn, Twitter, etc. A wide selection of journals (inclusive of 9 subjects, more than 200 journals)

Providing 24-hour high-quality service

User-friendly online submission system

Fair and swift peer-review system

Efficient typesetting and proofreading procedure

Display of the result of downloads and visits, as well as the number of cited articles

Maximum dissemination of your research work

Submit your manuscript at: http://papersubmission.scirp.org/

Or contactwja@scirp.org 